\title{
Natural infection with Fasciola hepatica (Linnaeus, 1758) in the European bison (Bison bonasus) in Białowieża National Park, Poland
}

\author{
B. KIZIEWICZ
}

\begin{abstract}
Department of General Biology, Medical University, Medical Faculty of Bialystok, 2C Mickiewicza (st.), 15-222 Białystok, Poland, E-mail: bozena.kiziewicz@umb.edu.pl
\end{abstract}

\begin{abstract}
Summary
The aim of our study was to determine prevalence of appearance of Fasciola hepatica L. among European bison Bison bonasus selected in Białowieża National Park, Poland from 2001 to 2006 . The analyzed ITS-1 and ITS-2 sequences of nuclear DNA of Fasciola hepatica have a length of $433 \mathrm{bp}$ and an AT content of $47.8 \%$ and a length of $365 \mathrm{bp}$ and an AT content of $51.2 \%$ respectively. Among 178 bison liver fluke was found in liver of 63 (35.3\%) individuals including as follow: in $39(21.9 \%)$ adults, $11(6.1 \%)$ juveniles and $13(7.3 \%)$ calves. Results of researches are as follow: prevalence of infection of Fasciola hepatica among bison in Białowieża National Park between 2001 - 2006 oscillated about 35.3\%. The most extensive invasion of fascioliasis was observed in adult animals $(21.9 \%)$. We pay attention that between infected animals were calves 13 (7.3\%). Conclusions: The obtained results referring to infection of bison within the Białowieża National Park, Poland of $F$. hepatica are very interesting. The epidemiological importance of these finding is evident, demonstrating the fascioliasis expansion in restricted or protected areas, as National Parks such as Białowieża National Park, habitat of this wild host, and where no domestic animals are present.
\end{abstract}

Keywords: Fasciola hepatica; nuclear DNA; Bison bonasus; Białowieża National Park; Poland

\section{Introduction}

Fascioliasis caused by liver fluke Fasciola hepatica is a worldwide parasitic disease common in ruminants, especially cattle, buffaloes, sheep, goats, and swine. It may, however, affect bison, suckers, black rat, ostriches, hares and humans (Mas-Coma et al., 1998; 1999; Valero et al., 1999). Once ingested, parasites migrate through the liver parenchyma to reach the bile ducts. In ruminants, the liver is damaged and condemned, and the subclinical and chronic disease usually results in decreased production of meat, milk and wool, secondary bacterial infections, fertility problems, and great expenses with anthelmintics (Marques \& Scroferneker, 2003; Faria et al., 2005). Fasciola hepatica has a cosmopolitan distribution. It can be assumed that liver fluke is European origin, with the snail Limnaea truncatula as the original intermediate host. Some authors suggest the potential of this wild host in the fascioliasis transmission (Bargues et al., 2001, 2012; Khoubbane et al., 2004; Mas-Coma et al., 2009). The liver fluke Fasciola hepatica plays an important role as a parasite of wild and farm animals. Humans become infected after eating aquatic plants on which encysted metacercarias are present or by drinking contaminated water. Over the period 1970 - 1990 human cases were reported in 42 countries, and the World Health Organization now recognizes fascioliasis as a dangerous disease in humans. The Fasciola hepatica is responsible for human fascioliasis, a major parasitic disease widely distributed throughout the world affecting globally several million of people, while a further 180 million are at risk (Esteban et al., 2002; Saba et. al., 2004). In hypo- to hyper-endemic areas of Central and South America, Europe, Africa and Asia, human fascioliasis presents a range of epidemiological characteristics related to a wide diversity of environments (Mas-Coma 2005). Circle of hosts of this liver fluke is coming wider every year also in East Europe.

For research a population of wild European bison Bison bonasus living in Białowieża National Park, Poland were chosen.

The aim of our study was to determine prevalence of appearance of liver fluke Fasciola hepatica L. among European bison Bison bonasus selected in Białowieża National Park in $2001-2006$. 
Tab. 1. Prevalence of infection with Fasciola hepatica by age - group in Bison bonasus in Białowieża National Park, Poland, 2001 - 2006

\begin{tabular}{|c|c|c|c|c|c|c|c|c|c|c|}
\hline \multirow[t]{2}{*}{ Period } & \multirow{2}{*}{$\begin{array}{c}\text { Number of } \\
\text { examined } \\
\text { animals }\end{array}$} & \multirow{2}{*}{$\begin{array}{c}\text { Percentage of } \\
\text { examined } \\
\text { animals }\end{array}$} & \multicolumn{8}{|c|}{ Number of infected animals } \\
\hline & & & Individuals & $\%$ & Adults & $\%$ & Juveniles & $\%$ & Calves & $\%$ \\
\hline Dec 2001 - Mar 2002 & 35 & 19.6 & 6 & 17.1 & 2 & 5.7 & 0 & 0 & 4 & 11.4 \\
\hline Dec 2002 - Mar 2003 & 40 & 22.4 & 15 & 37.5 & 12 & 30 & 2 & 5 & 1 & 2.5 \\
\hline Oct 2003 - Mar 2004 & 35 & 19.6 & 11 & 31.4 & 8 & 22.8 & 3 & 8.5 & 0 & 0 \\
\hline Dec $2004-$ Apr 2005 & 34 & 19.1 & 9 & 26.4 & 9 & 26.4 & 0 & 0 & 0 & 0 \\
\hline Nov 2005 - Mar 2006 & 34 & 19.1 & 22 & 64.7 & 8 & 23.5 & 6 & 17.6 & 8 & 23.5 \\
\hline In average & 35.60 & & 12.60 & & 7.80 & & 2.20 & & 2.60 & \\
\hline Total number & 178 & 100 & 63 & 35.3 & 39 & 21.9 & 11 & 6.1 & 13 & 7.3 \\
\hline
\end{tabular}

\section{Material and methods}

Prevalence of invasion of the adult liver fluke Fasciola hepatica (Animalia, Trematoda, Digenea, Fasciolidae, Fasciola, Fasciola hepatica Linnaeus, 1758) in common ducts bile of liver European bison Bison bonasus (białowieski) in Białowieża National Park, Poland was investigated in 2001 - 2006. Within Polish area of Białowieża National Park the population of bison in herd consists about 351 animals and within Belorussian area about 275 animals (Krasińska \& Krasiński, 2004).

Samples of common ducts bile of liver of (necropsies) bison from 3 months-old to 17 years old killed during selection match were received post-mortem (autopsy). The method directly dissected the common ducts bile of liver were examined where macroscopic adult liver fluke Fasciola hepatica was found. Molecular techniques were used in Laboratory Departamento de Parasitologia, Facultad de Farmacia, Universidad de Valencia, Spain to verify that the liver fluke was Fasciola hepatica.

The results were subjected to statistical analysis using $\chi^{2}$ test. $\chi^{2}$-test was used to determine the significance of differences in mean prevalence of Fasciola hepatica in liver of bison in researched years. The samples met the criteria at $\mathrm{P} \leq 0.05$.

\section{Results}

The analyzed ITS-1 and ITS-2 sequences of nuclear DNA have a length of $433 \mathrm{bp}$ and an AT content of $47.8 \%$ and a length of $365 \mathrm{bp}$ and an AT content of $51.2 \%$ respectively. The prevalence of invasion of the liver fluke $F$. hepatica in the ducts bile of liver of bison in the $2001-2006$ is presented in Table 1, Figures 1and 2. In winter from December 2001 to March 2002 out of 35 bison specimens involved in the study, $6(17.1 \%)$ individuals including as follow: $2(5.7 \%)$ adult and $4(11.4 \%)$ calves had liver flukes, which amounted $17.1 \%$ of tested bison population. From December 2002 to March 2003 from among 40 bison, the liver fluke was detected in $15(37.5 \%)$ individuals including as follow: $12(30 \%)$ adults, 2 (5\%) juveniles and $1(2.5 \%)$ calf. Prevalence of infection was $37.5 \%$ of population.

From October 2003 to March 2004 out of 35 specimens examined, $11(31.4 \%)$ individuals including as follow: 8 $(22.8 \%)$ adults and $3(8.5 \%)$ juveniles were infected by parasites, which amounted $31.4 \%$ of tested animals.

Of the 34 bison examined from December 2004 to April 2005, only $9(26.4 \%$.) adult animals were infected by liver fluke. Prevalence of infection was $26.4 \%$ of tested population.

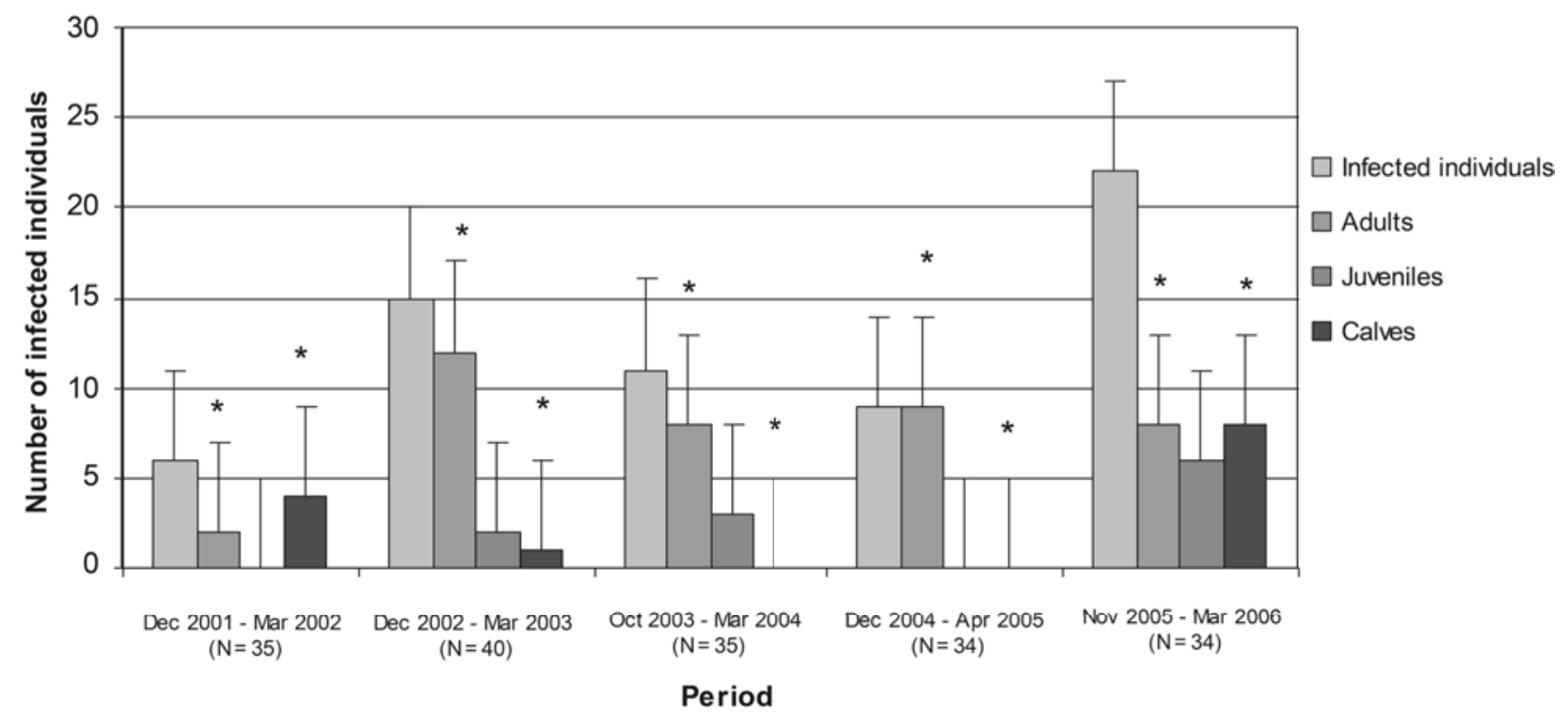

Fig. 1. The age effect of the infection of Fasciola hepatica in Bison bonasus in Białowieża National Park, 2001 - 2006. Significance of differences in statistical analysis $* \mathrm{P} \leq 0.05$. 


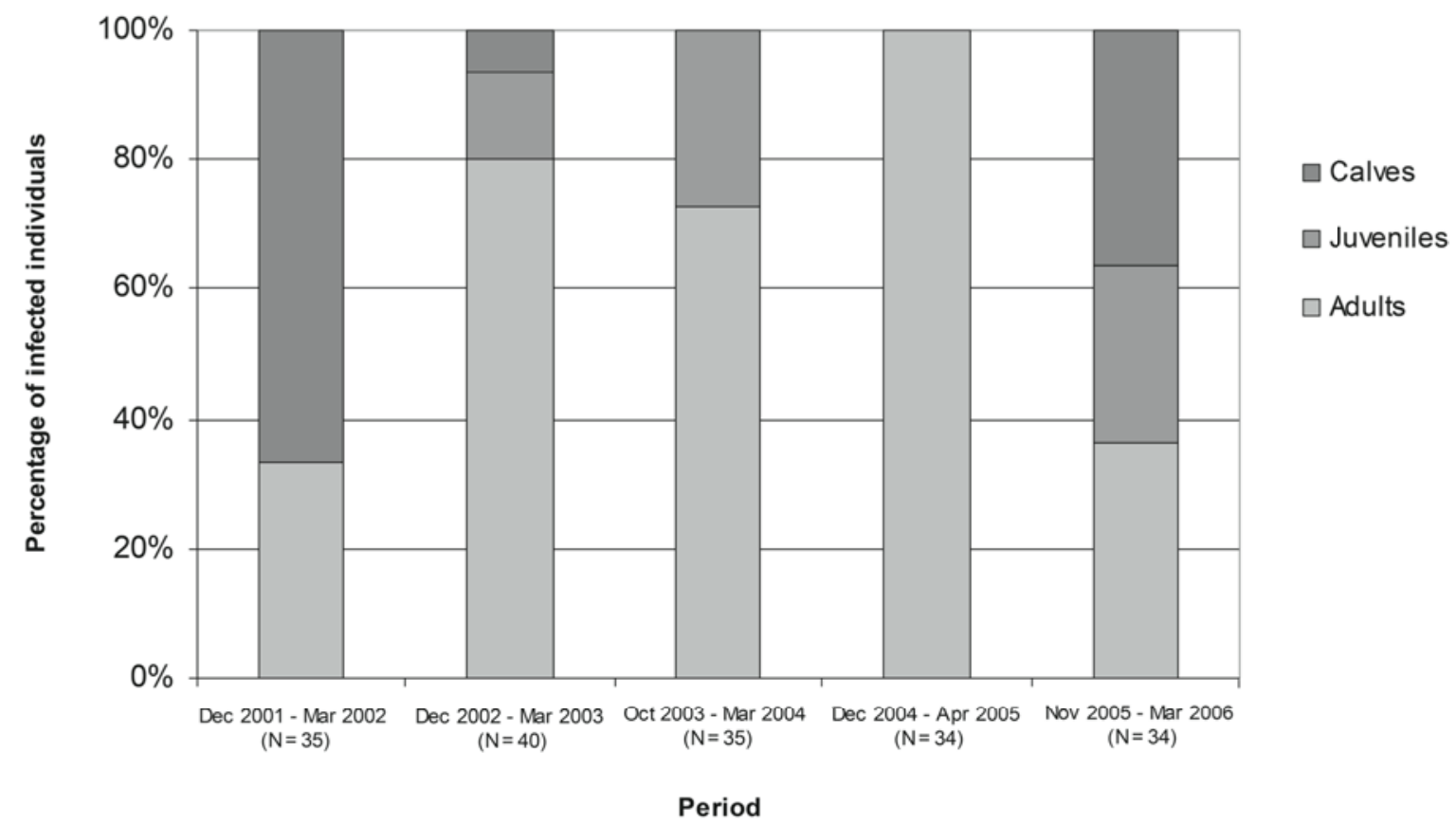

Fig. 2. Prevalence of Bison bonasus in each age groups infected by Fasciola hepatica in Białowieża National Park, 2001 - 2006

From November 2005 to March 2006 anatomized 34 of bison. Liver fluke was found in $22(64.7 \%)$ individuals including as follow: in $8(23.5 \%)$ adult and $6(17.6 \%)$ juveniles, $8(23.5 \%)$ calves.

In the $2001-2006$, among 178 bison the liver fluke $F$. hepatica was found in ducts bile of liver of $63(35.3 \%)$ individuals including as follow: in $39(21.9 \%)$ adults, 11 (6.1\%) juveniles and $13(7.3 \%)$ calves. The main result of our study was that prevalence of infection of liver fluke $F$. hepatica, among European bison Bison bonasus in Białowieża National Park between 2001 - 2006 oscillated about $35.3 \%$. The most extensive invasion of fascioliasis was observed in adult animals $(21.9 \%)$. The most results were statistically significant $(\mathrm{P} \leq 0.05)$. The prevalence of $F$. hepatica invasions was significant in $2001-2006$ in age groups of bison as follow: adults $(\mathrm{P}=0.0001)$ and calves $(\mathrm{P}=0.0156)$.

\section{Discussion}

Fascioliasis is a parasitic disease caused by the trematodes Fascila hepatica and Fasciola gigantica that affects both animals and humans. Fasciola hepatica has a worldwide distribution with a high prevalence in livestock in different endemic areas in the world. On the other hand, F. gigantica is more limited to tropical areas, namely Africa, the Middle East, Eastern Europe and Eastern and Southern Asia. In Europe, fasioliasis is considered an endemic disease in farm animals, even though its distribution may be extended, as well as its infective capability, due to its ability to affect wild herbivores and rodents with different degrees of intensity (Mas-Coma et al., 2009). The European bison (Bison bonasus) is the most of Asia but presently it is limited to reserves and parks of Poland and Belarus
(Krasińska \& Krasiński, 2004).

The material for macroscopic and molecular analysis of liver fluke specimens was obtained from bile ducts of liver of bison. It should have been noticed that bison in the anatomized population were wild living under pressure of natural selection. Natural selection affects old individuals much more than young ones due to characteristic decrease of body weight and receptive in infections. A genotypic analysis of the internal transcribed spacers ITS-1 and ITS2 of the nuclear DNA of adult liver flukes obtained by necropsy of wild bison from Białowieża National Park, Poland was performed. The analyzed ITS-1 and ITS-2 sequences have a length of $433 \mathrm{bp}$ and an AT content of $47.8 \%$ and a length of $365 \mathrm{bp}$ and an AT content of 51.2 $\%$ respectively. The comparison of the ITS- 1 sequences to other sequences published for $F$. hepatica demonstrate that the analyzed sequences are identical to those of the genotype for $F$. hepatica. The comparison of the ITS-2 sequences published for both $F$. hepatica and $F$. gigantica, from other hosts and other countries, also demonstrate complete homology with European original genotype for $F$. hepatica that differentiate it from the genotype of $F$. gigantica (Artigas et al., 2004; Semyenova et al., 2005; Mas-Coma et al., 2009).

Within the studied area of Białowieża National Park the prevalence liver fluke-induced infection has become lower, compared with the $90 \mathrm{~s}$ of the previous century (Dróżdż et al., 2002). This is probably the result of weather - dry and hot summers. Four free living European bison shot in 1997 within Lutowiska Forestry District in Bieszczady Mountains, Poland were infected with 9 species of nematode. Among all necropsies animals only in the excrement of one of them eggs of Fasciola hepatica were found (Dróżdż et al., 2000). Fascioliasis in Poland occurs in different inten- 
sity, which is firstly dependent of region and season when the research was done. Earlier observation of cattle in Warmińsko-Mazurskie Voivodeship, Poland has also revealed a decline in the prevalence of infection by liver fluke in 1980 - 1991. Fasciola hepatica was found in 28.2 $\%$ of the population of animals (Uradziński \& Radkowski, 1992). Recently visible increase of infection by Fasciola hepatica in this area has been showed (Michalski \& Romaniuk, 2000).

The investigations on Fasciola hepatica presence in cattle of Lubelskie Voivodeship, Poland demonstrated different results. Within studied area prevalence of infection of liver fluke in cattle underwent in lately of years considerable growth in comparison to 90 years past of century. In the next period prevalence of infection of Fasciola hepatica in that field was lower - between $4.1-24.3 \%$.

Liver fluke occurs in bison very often and in average $44 \%$ of researched animals are infected (Deryło et al., 2001). Strong invasion of this parasite gives clear clinical manifestation in bison like thinning down, dysentery and poor growing. Parasite is common between domestic ruminants. In North America, Fasciola hepatica is commonly found in domestic ruminants also but is uncommon in wild ruminants (Pybus, 2001). In bison Fasciola hepatica has been reported from one American bison in Montana, USA (Locker, 1953) and one American bison in Wyoming, USA (Bergstrom, 1967). The American bison is a native ruminant of North America and is a host of numerous parasites that also infect a variety of other wild and domestic ruminants. The experimental study was conducted by Foreyt and Drew (2010) to evaluate the susceptibility of American bison to liver flukes Fasciola hepatica and Fascioloides magna. Based on these results, bison are highly susceptible hosts for Fasciola hepatica because all inoculated bison became infected. Therefore evaluation for Fasciola hepatica infection should be accomplished in enzootic areas where bison are pastured in the vicinity of infected cattle, sheep or goats. It is suggested that reinvasion between bison, cattle, sheep and goats on common grass-lands can happen (Kiziewicz et. al., 2004; Krasińska \& Krasiński, 2004; Foreyt \& Drew, 2010). The results referring to infection of bison within the Białowieża National Park, Poland of Fasciola hepatica are very interesting. The epidemiological importance of these finding is evident, demonstrating the fascioliasis expansion in restricted or protected areas, as National Parks such as Białowieża National Park, habitat of this wild host, and where no domestic animals are present. It is suggested to continue studies on liver fluke Fasciola hepatica not only on domestic ruminants but also on wild animals.

\section{Conclusions}

The obtained results referring to infection of bison within the Białowieża National Park, Poland of $F$. hepatica are very interesting. The epidemiological importance of these finding is evident, demonstrating the fascioliasis expansion in restricted or protected areas, as National Parks such as
Białowieża National Park, habitat of this wild host, and where no domestic animals are present.

\section{Acknowledgments}

I am grateful to prof. Małgorzata Krasińska from Mammal Research Institute PAS in Białowieża and dr. Zbigniew A. Krasiński from Białowieża National Park in Białowieża, Poland and to prof. Santiago Mas-Coma and his Team from Departamento de Parasitologia, Facultad de Farmacia, Universidad de Valencia, Spain.

\section{References}

Artigas, P., Periago, M. V., Kiziewicz, B., Bargues, M. D., MAS-COMA, S. (2004): Molecular characterization of Fasciola hepatica from the wild natural host Bison bonasus of Poland. In Programme and Abstracts of IX European Multicoloquium of Parasitology, July 18 - 23, 2004. Valencia, Spain, 2001, pp. $287-288$

Bargues, M. D, Vigo, M., Horak, P., Dvorak, .J, Patzner, R. A., Pointier, J. P., Jackiewicz, M., MeierBrooK, C., MAS-COMA, S. (2001): European Lymnaeidae (Mollusca: Gastropoda), intermediate hosts of trematodiasis, based on nuclear ribosomal DNA ITS-2 sequences. Inf. Gen. Evol., 1: 85 - 107

Bargues, M. D., Artigas, P., Khoubbane, M., Ortiz, P., NAGIRA, C., MAS-COMA, S. (2012): Molecular characterization of Galba truncatula, Lymnaea neotropica and L. schirazensis from Cajamarca, Peru and other potential role in transmission of human and animal fascialiasis. Parasit. Vectors, 15(5): 174. Retrieved from http://www.parasitesandvec tors.com/conten/5/1/174. DOI: 10.1186/1756-3305-5-174

Bergstrom, R. C. (1967): Sheep liver fluke, Fasciola hepatica (L. 1758) from buffalo, Bison bison (L. 1758) in western Wyoming. J. Parasitol., 53: 724

Deryło, A., KozŁowska-ŁóJ, J., Szylman, P., Najda, N., SeniUK, A., WAsilewsKi, K. (2001): Extensiveness of infection of Fasciola hepatica L. in cattle in Lublin's Voivodeship in 1993 - 2001. Wiad. Parazytol., 47: 775 - 778 (In Polish)

DrożDż, J., DEMiaszKiewicz, A. W., LACHOWICZ, J. (2000): Helminthofauna of free living European Bison bonasus (L.) in Bieszczady mountains (Karpation mountains, Poland. Wiad. Parazytol., 46: 55 - 61 (In Polish)

DrożDż, J., DemiaszKiewicz, A. W., LACHOWICZ, J. (2002): The forming stomachic-intestinal nematode fauna of free-living bison in Białowieża Primeval Forest by the last 17 years. Wiad. Parazytol., 48: 357 - 381 (In Polish)

Esteban, J. G., GonzÁlez, C., Bargues, M. D., Angles, R., SÁnches, C., NÁQuira, C., MAs-Coma, S. (2002): High fascioliasis infection in children linked to a manmade irrigation zone in Peru. Trop. Med. Int. Health, 7(4): 339 - 348. DOI: 10.1046/j.1365-3156.2002.00870

FARIA, R. N., CURY, M. C., LIMA, W. S. (2005): Prevalence and dynamics of natural infection with Fasciola hepatica (Linnaeus, 1758) in Brazilian cattles. Revue Méd. Vét., 156(2): $85-86$ 
Foreyt, J. W., DREW, M. L. (2010): Experimental infection of liver flukes, Fasciola hepatica and Fascioides magna, in Bison (Bison bison). J. Wild. Dis., 283 - 286

Khoubbane, M., Sevilla, G., Kiziewicz, B., Bargues, M. D., MAS-COMA, S. (2004): Embryogenesis and viability of Fascila hepatica eggs from the wild natural host Bison bonasus of Poland. In Programme Abstracts of IX European Multicoloquium of Parasitology, July 18 - 23, 2004. Valencia, Spain, pp. $287-288$

KiziewicZ, B., KRAsiŃsKA, M., KRAsiŃsKi, Z. A. (2004): Prevalence of Fasciola hepatica L. induced infection in European bison Bison bonasus in Białowieża Primeval Forest in the years $2001-2004$. In Abstracts of Proceeding of the Conference: European Bison Conservation. Mammal Research Institute PAS, Centre of Excellence BIOTER, September 30 - October 2, 2004. Białowieża, Poland, pp. $62-64$

KrAsińsKA, M., KRASIŃSKI, Z. A. (2004): Bison natural monograph. Studio Fotografii Przyrodniczej „Hajstra”, Najkomp, Warszawa (In Polish)

LOCKER, B. (1953): Parasites of bison in Northwestern USA. J. Parasitol., 39: 58 - 59

MARques, S. M., SCROFERneKer, M. L. (2003): Fasciola hepatica infection in cattle and buffaloes in the State of Rio Grande do Sul, Brazil. Parasitol. Latinoam., 58: 169 - 172

MAS-COMA, S. (2005): Epidemiology of fascioliasis in human endemic areas. J. Helminthol., 79(3): 207 - 216

Mas-Coma, S., Angles, R., Esteban, J. G., Bargues, M. D., Buchon, P., Franken, M., Strauss, W. (1999): The Northern Bolivian Altiplano: a region highly endemic for human fascioliasis. Trop. Med. Int. Health, 4: $454-467$. DOI: 10.1046/j.1365-3156.1999.00418.x

Mas-Coma, S., Fons, R., Feliu, C., Bargues, M. D., VAlero, M. A., Galán-Puchades, M. T. (1998): Small mammals as natural definitive hosts of the liver fluke,
Fasciola hepatica Linnaeus, 1758 (Trematoda; Fasciolidae): A review and two new records of epidemiologic interest on the Island of Corsica. Rev. Parasitol., 5: 73 - 78 Mas-Coma, S., Valero, M. A, Bargues, M. D. (2009): Chapter 2. Fasciola, lymnaeids and human fascioliasis, with a global overview on disease transmission, epidemiology, evolutionary genetics, molecular epidemiology and control. Adv. Parasitol., 69: 41 - 146. DOI: 10.1016/ S0065-308X(09)69002-3

MiCHALSKI, M., ROMANIUK, K. (2000): The occurrence of liver fluke in the milk of cows in north eastern of Poland. Med. Wet., 56(3): $182-184$

PyBus, M. J. (2001): Liver flukes. In: SAMUEL, WM, Pybus, M., Kocan, A. A. (Eds) Parasitic diseases of wild mammals. Iowa State University Press, Ames, Iowa, pp. $121-149$

Saba, R., Korkmaz, M., Inan, D., MamikoĞlu, L., Turhan, F., Günseren, R., Cevicol, C., KabaAlioĞlu, A. (2004): Human fascioliasis. Clin. Microbiol. Infect. Dis., 10: $385-387$

Semyenova, S. K., Mrozova, E. V., Vasilyev, V. A., Gorokhov, V. V., Moskvin, A. S., Movsessyan, S. O., RYSKOV, A. P. (2005): Polymorphism of internal transcribed spacer 2 (ITS-2) sequences and genetic relationship between Fasciola hepatica and F. gigantica. Acta Parasitol., 50(3): $240-243$

URADZIŃSKI, J., RADKOWSKI, M. (1992): The occurrence parasites infection in animals Warmińsko- Mazurskie Voivodeship in 1980 - 1991. Med. Wet., 48: 564 - 569 (In Polish)

Valero, M. A., Marcos, M. D., Comes, A. M., Sendra, M., MAS-COMA, S. (1999): Comparison of adult liver flukes from highland and lowland populations of Bolivian and Spanish sheep. J. Helminthol., 73: 341 - 345 